IdeAs

Idées d'Amériques

16 | 2020

Les marges créatrices : intellectuel.le.s afro-

descendant.e.s et indigènes auX Amériques, XIX-XXe siècle

\title{
Donald Trump et l'écosystème des médias conservateurs : analyse d'une relation symbiotique
}

Sébastien Mort

\section{OpenEdition}

Journals

Édition électronique

URL : http://journals.openedition.org/ideas/9843

DOI : $10.4000 /$ ideas.9843

ISSN : 1950-5701

Éditeur

Institut des Amériques

Référence électronique

Sébastien Mort, « Donald Trump et l'écosystème des médias conservateurs : analyse d'une relation symbiotique », IdeAs [En ligne], 16 | 2020, mis en ligne le 01 octobre 2020, consulté le 18 octobre 2020 URL : http://journals.openedition.org/ideas/9843 ; DOI : https://doi.org/10.4000/ideas.9843

Ce document a été généré automatiquement le 18 octobre 2020

\section{(c) (1) $\Theta \Theta$}

IdeAs - Idées d'Amériques est mis à disposition selon les termes de la licence Creative Commons Attribution - Pas d'Utilisation Commerciale - Pas de Modification 4.0 International. 


\title{
Donald Trump et l'écosystème des médias conservateurs : analyse d'une relation symbiotique
}

\author{
Sébastien Mort
}

1 Face aux taux d'audience records qu'enregistre la matinale de Fox News au printemps 2020, Donald Trump réagit par un tweet particulièrement enthousiaste: «Ouah! @Foxandfriends écrase la concurrence [...] dans l'audimat des programmes du matin. Une vraie raclée, mais c'est ce qu'on obtient quand on traite "Trump" équitablement!». Si ce tweet semble à première vue n'être que l'expression de la mégalomanie du $45^{\mathrm{e}}$ président, il est en fait révélateur des liens consubstantiels que celui-ci a tissés avec Fox News. Car le rôle du réseau câblé conservateur dans les opérations de l'actuelle Maison Blanche ne se résume pas simplement à relayer les messages de l'administration: il consiste aussi et surtout à forger une image de la réalité qui soit conforme au message présidentiel, de façon à conforter Trump dans l'idée de sa réussite, une démarche qui résulte d'intérêts bien compris de la part de Fox, car plus Trump apparaît comme un président qui "gagne ", plus l'audimat du réseau est élevé. Au-delà de Fox, Trump entretient, à des degrés divers, des liens similaires avec la grande majorité des médias conservateurs, qui, dans leur ensemble, lui apportent un soutien inconditionnel.

Une telle relation symbiotique entre un président et des médias d'information est une situation proprement inédite. Si jusqu'en 2015, les talkshows radiophoniques tels que le Rush Limbaugh Show et les émissions d'analyse politique diffusées en prime time sur Fox comme The O'Reilly Factor ne se rangent pas systématiquement derrière les élites républicaines, c'est que leur légitimité politique et leur viabilité commerciale dépendent de la capacité des animateurs à maintenir un positionnement contestataire vis-à-vis d'un ordre politique et sociétal sur lequel ils considèrent que démocrates et forces progressistes exercent une influence indue. À leurs yeux, le Grand old Party (GOP) est certes le parti qui défend le mieux les intérêts du conservatisme, mais ses élites sont trop souvent enclines à céder au compromis. Ainsi, il faut constamment leur 
rappeler leur engagement envers le conservatisme dans sa forme la plus radicale, fût-ce par l'opposition frontale et agressive à certaines figures jugées trop modérées. Du reste, si les publics de ces émissions adhèrent à ce conservatisme fondamentaliste, il n'en va pas forcément de même pour l'ensemble de l'électorat républicain. Ce dernier ne se confond d'ailleurs pas entièrement avec les publics de Fox ou de Limbaugh, qui euxmêmes ne sont pas acquis au GOP de façon systématique. Jusqu'en 2015, la trahison idéologique et le risque commercial qu'aurait constitué le ralliement sans condition de ces médias au pouvoir républicain explique pourquoi les relations sont fluctuantes et parfois distantes.

\section{Avec Trump, intégration des médias conservateurs au dispositif politique de la Maison Blanche}

Ces relations changent lorsque Trump annonce officiellement son intention de briguer l'investiture républicaine puis, plus tard, lorsqu'il accède à la Maison Blanche. L'autoritarisme dont il est porteur entre en très forte résonance avec celui des animateurs de Tucker Carlson Tonight ou de The Ingraham Angle (Fox). Ces programmes d'analyse politique diffusées en prime time appartiennent au genre de «l'émission de tapage politique » (outrage programming), dont l'objectif n'est pas tant de défendre le conservatisme que de susciter l'indignation du public en créant le scandale (outrage) de façon tapageuse, à grand renfort d'attaques ad hominem, d'invectives et d'exagérations grossières et grandiloquentes ${ }^{1}$. Dès lors que Trump s'impose comme leader incontesté du Parti républicain, le public des émissions d'outrage se confond avec l'électorat républicain. Alors qu'avant 2015, le soutien inconditionnel aux élites républicaines aurait compromis la légitimité politique et la rentabilité commerciale de ces émissions, dans l'ère Trump, ce même soutien est précisément gage de succès.

4 Les médias conservateurs assurent au discours trumpien une certaine ubiquité - pour ne pas dire une présence hégémonique - dans l'environnement informationnel, d'autant qu'à côté des médias historiques, sont apparus deux acteurs majeurs du secteur de la télévision : One America News Network (OANN) et le réseau Sinclair Broadcasting Group (SBG). Lancée en 2013 lors de la Conservative Political Conference, congrès annuel des conservateurs américains, OANN se veut être une chaîne d'information en continu dédiée à l'expression de voix conservatrices inaudibles sur les autres supports conservateurs. Au fil des années, elle s'est surtout muée en grande pourvoyeuse de théories du complot et de contenus falsifiés. Accessible dans quelque 35 millions de foyers américains bien qu'absente de l'offre de la majorité des bouquets câblés, la chaîne n'enregistre cependant que de faibles taux d'audience par rapport à Fox, dont elle n'est du reste qu'une bien pâle copie : peu de contenus originaux, absence de correspondants sur le terrain, visuels peu travaillés et transitions mal assurées. En revanche, les animateurs d'OANN dépassent nettement ceux de Fox dans leur rôle de thuriféraires de Trump, tant ils poussent la flagornerie à son paroxysme. Là où même Fox fait entendre des voix démocrates et progressistes, ne serait-ce que pour accentuer les antagonismes entre Trump et ses opposants, OANN ne donne la parole qu'à Trump et ses partisans.

5 En fait, OANN offre à Trump un territoire de repli quand sa relation avec Fox connaît des tensions et qu'il cherche à ce que ses positions soient validées. Ainsi, quand le discours de Fox n'est momentanément plus aligné sur le sien ou quand il n'est plus le 
seul objet des convoitises du réseau, OANN lui assure une loyauté indéfectible. Récemment, des rumeurs se font entendre au sujet d'un possible projet d'investissement de Trump dans le réseau afin de le dynamiser, élargir la distribution, attirer un public plus large et créer une réelle concurrence avec Fox afin de ramener cette dernière dans le rang, ou pour garantir à Trump un espace d'expression dédié en cas d'échec en novembre.

Groupe de télévision crée en 1971, SBG est quant à lui propriétaire de 249 stations de télévision locales affiliées aux grands réseaux hertziens et à Fox. Le réseau opère par un processus de cannibalisation de l'information télévisée locale particulièrement pernicieux car bien souvent, les téléspectateurs n'ont aucune idée que la filiale d'ABC ou CBS à laquelle ils sont fidèles appartient en fait à un conglomérat conservateur. Alors que la grille des programmes est traditionnellement définie par des négociations entre la station et le réseau parent, la direction de $\mathrm{SBG}$ s'ingère dans la programmation et impose à ses stations la diffusion de contenus explicitement favorables à Trump ou qui contribuent à créer les conditions d'une réception favorable de son message. La stratégie est d'autant plus efficace que les médias locaux sont très appréciés des Américains, dont près de la moitié leur font davantage confiance qu'aux médias nationaux ${ }^{2}$.

7 La stratégie de SBG relève donc d'un machiavélisme achevé car l'affiliation de ses stations aux réseaux hertziens lui permet d'avancer masqué. Convaincu en toute bonne foi qu'il suit l'actualité de son État ou de son comté sur la filiale d'un média d'information généraliste, le public se voit soudain gratifié de messages qui le mettent en garde contre la malhonnêteté des médias grand public, dénoncent la tyrannie du progressisme sur les campus ou font l'éloge de Trump. Le réseau influence également les contenus en exigeant que certaines séquences soient introduites par un script commun qui oriente l'interprétation des contenus, ou en imposant aux chaînes certaines séquences à diffuser obligatoirement (must-run), comme The Terrorism Alert Desk, qui assimile l'Islam et l'immigration au terrorisme et entretient la peur de menaces imminentes. En outre, le réseau a diffusé 15 entretiens exclusifs avec Trump sur des stations implantées dans les États pivots lors de l'élection présidentielle de 2016, aucun avec Hillary Clinton.

8 Outre le système de "portes tournantes » (revolving doors), qui garantit aux animateurs de Fox un emploi à la Maison Blanche lorsqu'ils quittent la chaîne, et les relations personnelles de Trump avec Sean Hannity et Lou Dobbs, présentateurs vedettes de Fox, les liens entre Trump et les médias conservateurs sont scellés par la convergence du discours, la défense d'un ordre du jour commun et par un processus de légitimation mutuelle par lequel animateurs et commentateurs vantent l'action du président, qui en retour fait l'éloge de leur succès commercial et reprend à son compte certains de leurs messages. À telle enseigne que Jane Meyer, journaliste d'investigation du New Yorker, qualifie les liens entre Trump et Fox de «relation intégrée », le réseau câblé ayant été incorporé aux activités de l'exécutif, notamment les animateurs des talkshows du matin (l'équipe de Fox \& Friends) et de début de soirée. Avec les talkshows radiophoniques tels que ceux qu'animent Limbaugh ou Mark Levin et le site d'information en ligne Breitbart, ces émissions constituent le cœur de la galaxie des médias conservateurs et sont au centre des relations avec Trump et la Maison Blanche.

9 Ce constat doit toutefois être nuancé car le soutien n'est pas unanime. Ainsi, des antagonismes très marqués existent sur Fox entre journalistes du service d'information 
- dont certains comme Sheppard Smith ont quitté la chaîne - et animateurs de talkshows, dont tous ne sont pas des inconditionnels purs et durs. Ainsi, l'animateur de Fox News Sunday Chris Wallace se montre particulièrement critique à l'égard de Trump et de son administration, et se démarque par la pugnacité avec laquelle il confronte ses invités à leurs incohérences. En août 2020, il déclare sans ménagement à Jason Miller, conseiller de campagne du président, que ce dernier se décrédibilise en refusant d'admettre qu'il est en train de perdre et qu'il lui faut rectifier le tir. En outre, là où certains médias ont abdiqué toute indépendance - comme c'est le cas d'OANN -, certains, à l'instar du Wall Street Journal, s'emploient à maintenir une certaine distance critique, et d'autres en sont devenus de farouches opposants. C'est le cas de Matt Drudge, fondateur de l'agrégateur d'information en ligne conservateur Drudge Report, qui a couvert la procédure d'impeachment de façon particulièrement agressive et hostile à Trump, amorçant par là un tournant éditorial très net car jusqu'alors, Drudge avait soutenu Trump avec ferveur et entretenait avec lui des liens étroits.

\section{Pandémie de COVID et mouvements de contestation contre les violences policières}

10 La pandémie de COVID et les manifestations contre les violences policières ont permis d'observer de façon plus détaillée les relations entre Trump et ces médias. Alors que l'épidémie commence à gagner les États-Unis, Fox se retrouve prise en étau entre la conscience accrue qu'a sa direction de la réalité de la crise sanitaire et le trumpisme invétéré des animateurs de ses programmes phares. Si la chaîne interdit à ses employés de prendre l'avion et suspend indéfiniment Trish Regan de Fox Business et le duo Diamond \& Silk, pour leurs déclarations abusives sur la réalité de l'épidémie, les animateurs de prime time continuent d'avoir carte blanche.

11 Hannity dénonce la prétendue politisation de l'épidémie par les médias grand public et les démocrates, et dépeint l'inquiétude pourtant légitime qu'elle suscite comme relevant de l'hystérie de masse. Selon lui, démocrates et médias grand public encouragent la propagation du virus et sont vus comme les «supporters du COVID ». Quand il ne minimise pas l'incidence du virus en l'assimilant à la grippe saisonnière, l'animateur présente l'épidémie comme une vendetta organisée contre Trump dans le but de provoquer une crise économique et lui nuire.

12 Ainsi, les talkshows du soir de Fox offrent un espace médiatique où les sentiments de méfiance et d'hostilité envers les récits officiels sont renforcés et légitimés et où s'élaborent des contre-récits qui font pièce aux récits dominants. Ce faisant, ces émissions entretiennent la mentalité obsidionale du public, c'est-à-dire que l'idée de l'Amérique éternelle, la "vraie » Amérique est assiégée par des forces hostiles. La façon dont chacun se positionne par rapport à l'épidémie et accepte ou non le dispositif de protection devient un marqueur d'identité, l'appartenance identitaire devenant plus importante que les enjeux sanitaires.

13 Toutefois, la chaîne amorce un virage quand Trump déclare le COVID-19 urgence nationale à la mi-mars. Après avoir nié l'importance de l'épidémie, Hannity adapte immédiatement son discours pour chanter les louanges du président dans la gestion de la crise : reprenant le refrain du «leadership Américain retrouvé », il centre son message sur les qualités de dirigeant du président. Ce qui compte pour Fox - tout au 
moins pour les animateurs des émissions les plus lucratives -, ce n'est donc pas tant la vérité que la mise en cohérence de la façon dont elle représente le réel avec le discours de l'administration, afin de défendre et perpétuer le récit-socle qui sous-tend la présidence de Trump : Trump est un président au leadership efficace, qui rétablit le panache de l'Amérique après des années de désastres.

Les manifestations contre les violences policières à la suite de l'assassinat par la police du citoyen africain-américain George Floyd en mai 2020 créent la discorde entre la Maison-Blanche et une partie des républicains au Congrès. Là où certains élus reconnaissent la légitimité des manifestations, au moins en apparence, Trump s'illustre par un tweet reprenant la déclaration d'un ancien chef de police ségrégationniste de Miami ("Quand les pillages démarrent, les tirs commencent»): refusant de reconnaître la légitimité du mouvement, Trump décrit les manifestants comme des voyous et des casseurs menaçant l'ordre public.

Les talkshows politiques de Fox lui emboittent le pas : leur analyse des manifestations ne se concentre que sur les scènes de dégradations matérielles, évacue leur dimension sociétale et ignore les revendications des manifestants ainsi que les failles systémiques qui mènent à ces manifestations. Illustre pour ses prises de position aux relents clairement racistes, lorsque les manifestations débutent, l'animateur de la tranche 20h00-21h00 Tucker Carlson affirme que « les éléments les pires ont pris le contrôle. Ils n'ont rien fait pour bâtir ce pays. Maintenant, ils sont en train de le détruire ». Arguant de ce que les Américains ont le droit de se défendre quand les pouvoirs publics renoncent à faire régner l'ordre, il incite les blancs à la défense armée et soutien Kyle Rittenhouse, le meurtrier présumé de deux manifestants du mouvement Black Lives Matter.

\section{Conclusion}

Par le déploiement d'un discours commun, fruit d'une coordination entre certaines personnalités médiatiques conservatrices de premier rang et le président lui-même, et à la faveur d'un processus continuel de légitimation mutuelle, Trump et l'écosystème des médias conservateurs ont scellé des relations symbiotiques sans précédent depuis l'après-guerre. Jamais un président et son parti n'ont reçu un soutien d'une envergure et d'une intensité telles de la part de médias, fût-ce de médias partisans. Le degré d'intégration des logiques médiatiques aux activités de l'exécutif, le roulement du personnel entre les médias et la Maison-Blanche, au point que le médiatique et le politique finissent par se confondre, et l'influence de figures médiatiques sur la conduite des affaires - souvent au détriment des experts - amènent à conclure que, si les médias conservateurs, et Fox au premier chef, sont désormais de facto des médias d'État (state-run media), l'État fédéral, en grande partie sous contrôle républicain, est quant à lui devenu un "État médiatique » (media-run state) dont l'ordre du jour et la rhétorique sont définis par des figures qui, au-delà de leurs allégeances idéologiques, poursuivent avant tout à leur intérêt économique. Si cette relation assure à Trump le soutien d'un électorat qui lui est totalement acquis et peut lui garantir le nombre de voix nécessaires pour l'emporter dans les États pivots qu'il lui faut gagner pour s'assurer un second mandat, cela se fait au prix d'un chaos qui prend des airs de guerre civile et de la vie de milliers d'Américains que l'inaction du président dans la crise sanitaire n'a pas permis de sauver. 


\section{NOTES}

1. Jeffrey M. Berry et Sarah Sobieraj, The Outrage Industry : Political Opinion Media and the New Incivility, Oxford, Oxford University Press, 2014.

2. Elisa Shearer (20/07/2020), "Local news is playing an important role for Americans during COVID-19 outbreak," Pew Research Center. https://www.pewresearch.org/fact-tank/2020/07/02/ local-news-is-playing-an-important-role-for-americans-during-covid-19-outbreak/

\section{AUTEUR}

\section{SÉBASTIEN MORT}

Maître de conférences en sociétés et cultures des États-Unis à l'Université de Lorraine et membre du Centre de Recherche sur les Médiations, Sébastien Mort travaille sur l'intersection entre politique, médias d'information et journalisme aux États-Unis, les médias conservateurs et le phénomène d'intimidation politique des journalistes dans l'ère Trump. Il a récemment publié "Les médias conservateurs dans la campagne de 2020 : un soutien unanime au président? " pour l'Institut Français de Relations Internationales. 